\title{
Role of paediatric assist device in bridge to transplant
}

\author{
Roland Hetzer ${ }^{1}$, Mariano Francisco del Maria Javier ${ }^{1}$, Eva Maria Delmo Walter ${ }^{2}$ \\ ${ }^{1}$ Department of Cardiothoracic and Vascular Surgery, Cardio Centrum Berlin, Berlin, Germany; ${ }^{2}$ Department of Cardiac, Thoracic, Transplantation \\ and Vascular Surgery, Hannover Medical School, Hannover, Germany \\ Correspondence to: Eva Maria Delmo Walter, MD, MSc, PhD. Department of Cardiac, Thoracic, Transplantation and Vascular Surgery, Hannover \\ Medical School, Carl-Neuberg-Straße 1, Hannover 30625, Germany. Email: eva.delmowalter@gmail.com.
}

Background: While heart transplantation has gained recognition as the gold standard therapy for advanced heart failure, the scarcity of donor organs has become an important concern. The evolution of surgical alternatives such as ventricular assist devices (VADs), allow for recovery of the myocardium and ensure patient survival until heart transplantation becomes possible. This report elaborates the role of VADs as a bridge to heart transplantation in infants and children ( $\leq 18$ years old) with end-stage heart failure.

Methods: A retrospective review of the medical records of 201 heart transplant recipients between May 1986 and September 2014 identified 78 children [38.8\%; mean age 7.2 (7.8 \pm 6.0$)$ years old; IQR: 2.6-11.8 years] with advanced heart failure who were supported with a VAD [left VAD (LVAD) =21; biventricular VAD $(B V A D)=57$ ] as a bridge to heart transplantation. Fourteen (17.9\%) patients were less than 1 year old; 15 (19.2\%) children had a cardiac arrest and underwent cardiopulmonary resuscitation, with 7 of these patients also requiring extracorporeal membrane oxygenation (ECMO) support prior to implantation of a VAD. The aetiology of heart failure was primarily cardiomyopathy (dilative, restrictive from endocardial fibrosis, idiopathic or toxic-induced), reported in 56 (71.8\%) patients. The VADs employed were primarily Berlin Heart EXCOR ${ }^{\circledR}(\mathrm{n}=63)$, HeartWare $(\mathrm{n}=13)$, Berlin Heart $\operatorname{INCOR}^{\circledR}(\mathrm{n}=1)$, and Toyobo $(\mathrm{n}=1)$.

Results: Mean duration of VAD support was 59 (133.37 \pm 191.57$)$ days (range, 1-945 days; IQR: 23-133 days) before a donor heart became available. The primary complication encountered while patients were being bridged to transplant was mediastinal bleeding $(7.8 \%)$. The main indication for pump exchanges was thrombus formation in the valves. There was no incidence of technical failure of the blood pump or driving system components. Skin infections around the cannulae occurred in $2.5 \%$. Adverse neurological symptoms (thromboembolism $11.1 \%$, cerebral haemorrhage 3.6\%) that occurred did not have any permanent neurological sequelae that could be detected on clinical examination in this study. Mean duration of followup was $9.4(10.3 \pm 7.6)$ years (IQR: $3.74-15.14$ years). Cumulative survival rates of patients bridged to transplantation with VAD were $93.6 \% \pm 2.8 \%, 84.6 \% \pm 4.1 \%, 79.1 \% \pm 4.7 \%, 63.8 \% \pm 6.2 \%, 61.6 \% \pm 7.1 \%$, and $52.1 \% \pm 9.3 \%$ at 30 days, 1, 5, 10, 15 and 20 years, respectively. There was no statistically significant difference $(\mathrm{P}=0.79)$ in survival rates of patients bridged to heart transplantation with VAD compared to those who underwent primary heart transplantation. Post-transplant survival rates stratified according to the type of VAD implanted and number of ventricles supported were not statistically different $(\mathrm{P}=0.93$ and 0.73 , respectively). In addition, post-transplant survival rates were not significantly different when age, gender and diagnosis were adjusted for. Furthermore, no statistically significant difference was found when posttransplant survival rates of children who had episodes of rejection were compared to those who did not have episodes of rejection.

Conclusions: The results in this series demonstrate that VADs satisfactorily support paediatric patients with advanced heart failure from a variety of aetiologies until heart transplantation. The data further suggests that patients bridged with VADs have comparable long-term post-transplant survival as those undergoing primary heart transplantation.

Keywords: Ventricular assist device (VAD); bridge to transplantation; orthotopic heart transplantation; paediatrics; dilative cardiomyopathy; myocarditis; end-stage congenital heart disease (CHD) 
Submitted Aug 18, 2017. Accepted for publication Dec 28, 2017.

doi: 10.21037/acs.2018.01.03

View this article at: http://dx.doi.org/10.21037/acs.2018.01.03

\section{Introduction}

In 1990, the Berlin group reported the first successful paediatric bridge to transplantation using a pulsatile paracorporeal left ventricular assist device (LVAD) in an 8 -year-old boy $(127 \mathrm{~cm}, 27 \mathrm{~kg})$ with end-stage heart failure and life-threatening ventricular tachyarrhythmia due to long-standing pressure overload from aortic valve stenosis and aortic coarctation. He was admitted in cardiogenic shock. Though he was supported with an adult-sized VAD, he made it to heart transplantation (Figure 1) (1). This successful event catalyzed the Berlin group to eventually innovate miniaturized pump systems appropriate for infants and children (2) and initiated further improvements and advances in heart failure therapy for this population (3-6). The ensuing decades have seen the increased application of Berlin Heart EXCOR assist device in children in profound heart failure as a bridge to transplantation or as a bridge to myocardial recovery (7-9). The longest duration of VAD support ever reported was 856 days before transplantation became feasible (10).

Over the last three decades, with improved perioperative care and advances in surgical techniques in paediatric and congenital heart surgery, many children have overcome their primary disease and survived well. Other children, however, may develop heart failure over time. This is true not only in those surgically corrected congenital heart diseases (CHDs), but also in those with cardiomyopathies.

While heart transplantation has gained recognition as the gold standard therapy for advanced heart failure, the scarcity of donor organs has become an important concern. The evolution of surgical alternatives such as VADs have enabled recovery of the myocardium and ensure patient survival until heart transplantation becomes possible.

This report elaborates the contribution of VADs as a bridge to heart transplantation in infants and children ( $\leq 18$ years old) with end-stage heart failure.

\section{Methods}

Between May 1986 and September 2014, 201 children with end-stage heart failure [mean age $9.4(10.3 \pm 7.6)$ years; IQR: 3.7-15.11 years] underwent heart transplantation.
Among these, VADs (LVAD $=21$; biventricular VAD $=57$ ) were implanted in 78 children $[38.8 \%$; mean age 7.2 (7.8 \pm 6.0$)$ years; IQR: $2.6-11.8$ years] as bridge to heart transplantation. Fourteen $(17.9 \%)$ patients were less than 1 -year old (median 0.33 days; range, 0.002-0.83 days); $15(19.2 \%)$ children had a cardiac arrest and underwent cardiopulmonary resuscitation, with 7 of these patients also requiring extracorporeal membrane oxygenation (ECMO) support (median duration of support 5 days; range, 2-31 days), prior to implantation of a VAD. The aetiology of heart failure included cardiomyopathy (dilative, restrictive from endocardial fibrosis, idiopathic or toxin-induced) seen in $56(71.8 \%)$, fulminant myocarditis in $14(17.9 \%)$, endstage CHD in $5(6.4 \%)$, post-cardiotomy ischemic heart failure in $2(2.6 \%)$, and tumour (LV fibroma) in 1 (1.2\%) (Table 1). Two patients had an extremely high pulmonary vascular resistance. One patient had a previous heart transplantation 10 years ago, and two had anthracyclineinduced cardiomyopathy. Mean duration of VAD support was 131 days (range, 1-945 days as of this report) before a donor heart became available.

The VADs employed to bridge the children to heart transplantation were primarily Berlin Heart EXCOR ${ }^{\circledR}$ $(\mathrm{n}=63)$, HeartWare $(\mathrm{n}=13)$, Berlin Heart $\operatorname{INCOR}^{\circledR}(\mathrm{n}=1)$, and Toyobo $(\mathrm{n}=1)$. The institutional review board approved this retrospective study and waived the need for patient consent.

\section{Berlin Heart EXCOR ${ }^{\circledR}$ Pediatric (Berlin Heart GmbH, Berlin, Germany)}

This system consists of a paracorporeal, pneumatic compressor-operated diaphragm pump with polyurethane valves $(10,15,25$ or $30 \mathrm{~mL}$ stroke volume) and silicon cannulae $(4,8,11)$. The larger pumps $(50,60$ and $80 \mathrm{~mL})$ are equipped with mechanical valves (Sorin, Milan, Italy). The stationary driving unit (IKUS) was used in all pumps, except when driving pressures $<250 \mathrm{mmHg}$ was required. In these cases, the $\mathrm{BHE}^{\circledR}$ mobile driving unit (Berlin Heart AG, Berlin, Germany) was used. Blood pumps with volumes of 10, 25, 30, 50, 60 and $80 \mathrm{~mL}$ were available from 1992 to 2011. In 2012, the $15-\mathrm{mL}$ blood pump was added and has been widely used since then. 


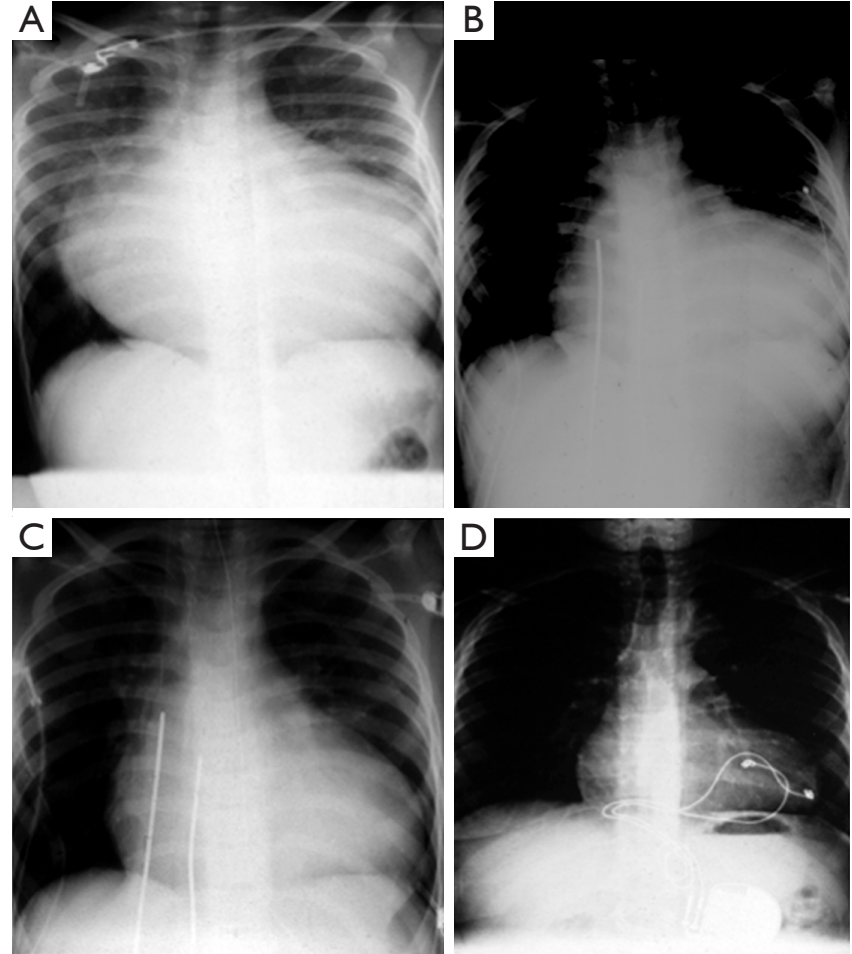

Figure 1 Chest X-ray of an 8-year old boy with end-stage left ventricular failure secondary from long-standing pressure overload due to severe aortic valve stenosis and aortic coarctation. (A) Before VAD implantation; (B) immediately post-VAD implantation; (C) before VAD explantation prior to heart transplantation; (D) after heart transplantation. VAD, ventricular assist device.

\section{HeartWare HVAD System (Framingham, MA, USA)}

The HeartWare HVAD is a miniaturized centrifugal continuous-flow pump that has a hybrid magnetic, hydrodynamic impeller suspension free from mechanical contact points. It provides up to $10 \mathrm{~L} / \mathrm{min}$ of flow. It is thin $(4.2 \mathrm{~mm})$, with flexible driveline and fatigue-resistant cables. The device is implantable and placed within the pericardium without the need for a pump pocket. The minimum body weight required is at least $25 \mathrm{~kg}$, to pump a minimum of $2 \mathrm{~L} / \mathrm{min}$, to avoid the risk of running an "empty pump".

\section{Berlin Heart INCOR ${ }^{\circledR}$ (Berlin Heart GmbH, Berlin, Germany)}

The Berlin Heart INCOR ${ }^{\circledR}$ was the first magnetically levitating, axial-flow pump combined with hydrodynamic force to achieve optimal performance. This device is

\begin{tabular}{|c|c|}
\hline 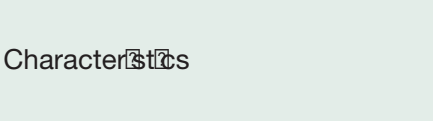 & 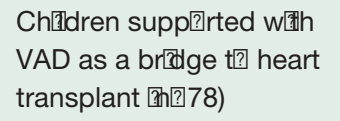 \\
\hline 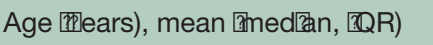 & 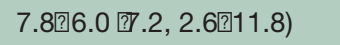 \\
\hline \multicolumn{2}{|l|}{ 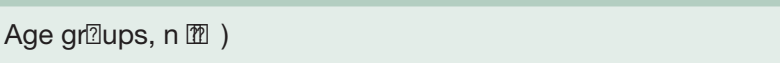 } \\
\hline 0?? 1 & 14四 7.9) \\
\hline ?10?5 & 15四 9.2) \\
\hline ?2010 & 11国 4.1) \\
\hline ?10?15 & 20整5.5) \\
\hline ?15 & 18哑3.1) \\
\hline \multicolumn{2}{|l|}{ Gender } \\
\hline Female & 46 \\
\hline Male & 42 \\
\hline \multicolumn{2}{|l|}{ 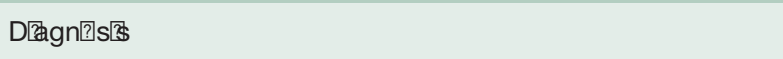 } \\
\hline DCMP & 56 \\
\hline 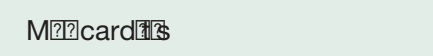 & 14 \\
\hline End? ?stagex? D & 5 \\
\hline 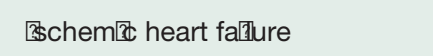 & 2 \\
\hline Tum?ur & 1 \\
\hline 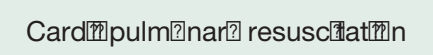 & 15 \\
\hline 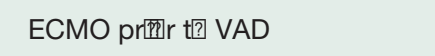 & 7 \\
\hline \multicolumn{2}{|l|}{ VADß\$?stems } \\
\hline 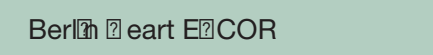 & 63 \\
\hline ? eartWare & 13 \\
\hline 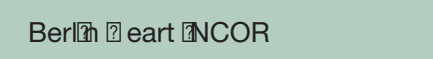 & 1 \\
\hline Tा?]?? b? & 1 \\
\hline LVAD & 51 \\
\hline BVAD & 27 \\
\hline
\end{tabular}

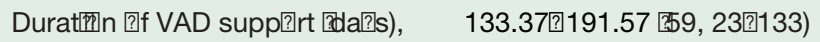

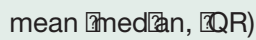

\begin{tabular}{|c|c|}
\hline 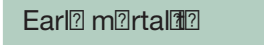 & 5 \\
\hline Late?m?rtal[त्t]? & 22 \\
\hline Re?transplantat俑n & 1 \\
\hline \multicolumn{2}{|l|}{ Graft?eject雨n } \\
\hline Acute & 22 \\
\hline Chr?nn民 & 0 \\
\hline
\end{tabular}


technologically advanced in its rational design without clinically significant technical defects, even with longterm use (12). The impeller is made into the rotor of the motor, and the magnetic flux, through the external stator rotates the impeller, while the impeller levitation is maintained through another electromagnetic system (12). The Berlin Heart INCOR has been implanted as a LVAD in a 17.8-year-old adolescent with dilated cardiomyopathy (DCMP) who underwent successful heart transplantation after 86 days of support.

\section{Toyobo (Nipro, Osaka, Japan)}

The Toyobo left ventricular assist system (LVAS; Nipro, Tokyo, Japan) is a paracorporeal, pneumatic, diaphragmtype LV assist system. The pumps are made of Toyobo TMseries segmented polyether polyurethane without a seam. The effective stroke volume is $70 \mathrm{~mL}$ and the maximum output in a mock system is $7 \mathrm{~L} / \mathrm{min}(13,14)$. The first clinical application of this device was in 1982, and it became commercially available in 1990 (15). In 2005, we admitted a 13.6-year-old boy with DCMP who was flown with a LVAD from Sapporo, Japan to Berlin, Germany, and was successfully bridged to transplantation after 82 days of VAD support.

\section{Choice of pumps, and indications, timing, and techniques for implantation}

Indications for implanting the VADs were (I) low cardiac output with metabolic acidosis; (II) rapid circulatory deterioration with a cardiac index $<2.0 \mathrm{~L} / \mathrm{min} / \mathrm{m}^{2}$ and/ or dependence on inotropes, particularly epinephrine; (III) mixed venous saturation of $<40 \%$; (IV) oliguria $(<1 \mathrm{~mL} / \mathrm{kg} / \mathrm{min})$; (V) critical peripheral perfusion; (VI) massive cardiac impairment as confirmed by echocardiography, despite maximal pharmacological treatment, with signs of early renal, hepatic and/or respiratory failure and high or progressive increase in B-type natriuretic peptide (BNP) or N-terminal proBNP levels (16).

The criteria for VAD implantation have been modified over time and shifted towards earlier implantation before irreversible organ damage is established, or after a few days on ECMO to obviate coagulation disorders and infection. This shift in criteria has also been facilitated by more recent technological improvements in long-term VAD therapy, such as the CARMEDA bioactive surface coating in EXCOR VAD pumps, development of apical and modified arterial cannulae, advanced coagulation monitoring, and individualized anticoagulation.

The decision regarding whether to implant a LVAD or BVAD was made in the operating theatre. The primary goal was to implant a LVAD. When patients failed to stabilize with a LVAD after coming off cardiopulmonary bypass, with signs of refractory right ventricular (RV) failure, the right $\mathrm{VAD}$ was added.

The choice of pump size was based on patient weight. The calculated pump flow for children is $120-150 \mathrm{~mL} / \mathrm{kg}$, and for adolescents, $100 \mathrm{~mL} / \mathrm{kg}$. The pump implantation guidelines were as follows: in patients weighing $<9 \mathrm{~kg}$, pumps with a stroke volume of $10 \mathrm{~mL}$; in patients weighing $7-14 \mathrm{~kg}$, pumps with a stroke volume of $15 \mathrm{~mL}$ were used; in those weighing 14-25 $\mathrm{kg}$, pumps with a stroke volume of 25 or $30 \mathrm{~mL}$; and in patients weighing $>30 \mathrm{~kg}$, adult pumps with a stroke volume of $50 \mathrm{~mL}$. In patients for whom the stroke volume of the pump was insufficient, the pump was replaced either in the operating theatre or at the bedside.

The surgical technique used for VAD implantation has been previously reported by our group $(8,9)$. Implantation of the BVAD in infants and small children has been challenging because of the small pericardial space, and positioning of the four cannulae after reconstructive operations could then become complex. As we gained more experience in VAD implantation in children, it became apparent that $\mathrm{LV}$ apical cannulation not only improves $\mathrm{LV}$ emptying but also decreases RV afterload, significantly improving biventricular unloading.

The main step forward made by our group over time was the introduction of apical cannulae. Before this development, the drainage of the heart was performed through the atrial cannulae on the left, inserted through Sondegaard's groove directly to the right. This configuration did not allow for complete drainage of the ventricle, and biventricular support became obligatory in almost all cases. With the introduction of apical cannulation of the LV, complete drainage of the left heart became feasible and, thus, biventricular support could be reserved for patients with more advanced heart failure.

It is important to implant the left apical cannula in such a way that it follows the axis of the LV by exiting the chest cavity towards the left chest wall. This technique avoids kinking of the cannula or luminal obstruction inside the $\mathrm{LV}$ cavity from direct contact with the septum or with the left lateral ventricular wall, which can be reliably assessed by echocardiography.

In infants, the tip of the aortic cannula should be 
directed along the axis of the aortic arch, so that it does not come into contact with the posterior wall of the ascending aorta. The cannulae should be of adequate length and well positioned at the exit sites in the chest to avoid kinking or distortion. The cannulae located inside the chest cavity are covered with a Gore-Tex membrane in anticipation of future redo thoracotomies. Adequate incisions should be made at the exit sites of the cannulae, adequately distanced from the sternal incision. This is a precaution to prevent spread of infection (if it occurs) to the sternal incision.

\section{VAD implantation techniques in patients with a single ventricle}

Children with end-stage heart failure who had undergone three-stage surgical palliation for a single ventricle present a very special subset for implantation of a VAD. In this series of patients, there were three patients with hypoplastic left heart syndrome who had an advanced heart failure secondary to a failing Fontan circulation. The issue therefore was the positioning of the inflow and outflow cannulae in the presence of several anastomoses and grafts or conduits. Implantation of a VAD was performed with cardiopulmonary bypass on a beating and perfused heart. Similar to the technique reported by Prêtre (17), the cavopulmonary anastomosis was taken down and the pulmonary stump was closed directly. The extracardiac conduit was divided in its middle part and its distal stump was used for implantation of the arterial line. A new capacity chamber (the inflow site) was then created and separated from the pulmonary artery (the outflow site). The VAD inflow cannula was placed in the apex of the single ventricle, the outlet cannula in the ascending aorta, and both cannula was brought through the skin and connected to a Berlin Heart pump.

We consider using the HeartWare HVAD (HeartWare, Framingham, MA, USA) in any patient with a body weight of $>25 \mathrm{~kg}$. Through a median sternotomy, under cardiopulmonary bypass and cardioplegic arrest, the inflow ring was buttressed with three doughnut-shaped felt "washers" to position the tip of the inflow cannula over the tricuspid subvalvar apparatus and towards the RV outflow tract. After suturing the ring to the myocardium and coring the ventricular wall for the HeartWare pump, an inflow cannula was inserted into the ventricle. The outflow graft was anastomosed to the ascending aorta using partial clamping. The second pump was inserted into the right atrium and connected to the pulmonary artery after closure of the pulmonary valve and atrial separation. The pump was then inserted through the diaphragmatic surface of the single ventricle, $3 \mathrm{~cm}$ from the tricuspid valve and towards the ventricular apex. The driveline was tunnelled through the right upper quadrant and then connected to the controller.

\section{Anticoagulation management after VAD implantation}

Management of anticoagulation has been modified since 2000. Before 2000, heparin activity was monitored using the activated clotting time to keep the activated clotting time between 140 and 160 seconds and antithrombin III substitution was performed if the activated clotting time fell below $70 \%$ of the target level.

At present, no postoperative anticoagulation is given for the first 8-24 hours. The effect is monitored two to four times daily, if necessary. For the next 48 hours, continuous unfractionated heparin infusion is administered to keep the activated partial thromboplastin time between 60 and 80 seconds. Thromboelastography, performed twice a week after VAD implantation, helps to identify the coagulation status and efficacy of heparin. It is very useful to evaluate hypo- or hyper-coagulation and to adjust the target value of activated partial thromboplastin time. Antithrombin III is substituted if activated partial thromboplastin time falls below $70 \%$ of the target level.

When oral feeding has been started and chest tubes have been removed, treatment with acetylsalicylic acid combined with dipyridamole (assuming a normal platelet number and function) in a weight-adjusted dose is started 1 week after implantation. Platelet aggregation tests are performed at least weekly, with target activation of $30 \%$. L-hirudin or argatroban is used in patients with heparin-induced thrombocytopenia type II. This is monitored by the platelet aggregation test with arachidonic acid (18).

Children remaining in hospital on VAD received low molecular weight heparin for long-term anticoagulation under monitoring of anti-Xa activity. After treatment with acetylsalicylic acid and dipyridamole was initiated, platelet aggregation tests were performed at least weekly, with target activation of $30 \%$ (19). Phenprocoumon with a target international normalized ratio of $3-3.5$ is given to adolescents who are discharged home on VAD.

Pump operation was monitored daily and, if necessary, readjusted to achieve optimal diaphragm movement. Daily transillumination of the pump chambers is a very important practice for early detection of the formation 
of small thrombi. In the presence of larger thrombi, the pump is exchanged in sterile conditions, in the operating theatre. Our current criteria for pump exchange include any thrombus formation in the left pump or in the left-side cannulae, or free-floating thrombi of any size in the right pump and cannulae.

Echocardiography is performed daily to monitor cardiac function, particularly during weaning. A prophylactic antibiotic with adequate anti-staphylococcal coverage (generally a second-generation cephalosporin) is administered in the preoperative, intraoperative, and immediate postoperative phases. Dressings are regularly changed around the cutaneous lines in sterile conditions. All transparent parts of the pumps and cannulae are examined for thrombus formation.

Hemofiltration or peritoneal dialysis is performed in cases of severe renal dysfunction. Ventilation therapy is continued until clinical, radiological, blood gas, and breathing parameters have normalized.

Our long experience has shown us that restoration of adequate circulation by the VAD leads to recovery of previously dysfunctional organs in most patients (16).

\section{Mobilization}

Infants and older children are mobilized as soon as their condition allows. After extubation, children are transferred to an intermediate ward for recovery. Small children dependent on the powerful, stationary IKUS driver are kept in hospital, whereas older children in whom the portable Berlin Heart EXCOR Pediatric ${ }^{\circledR}$ driver could be operated are discharged home whenever possible; these children go to school with the device.

\section{Allosensitization}

It is known that implantation of LVAD is associated with an increased risk of development of circulating anti-HLA class I and II antibodies (sensitization), detected by panel reactive antibody (20). The increased formation of HLA antibodies and the susceptibility to systemic infections are sustained by an immune dysfunction secondary to VAD implantation (21). Hence, it has been an institutional routine to perform desensitization on pediatric patients being bridged to heart transplantation with a VAD. To offset the incidence of rejection post-heart transplantation, we perform desensitization using $\mathrm{ABO}$ antigens blood compatible products, including irradiated and filtered, leukocyte-reduced packed red cells and fresh frozen plasma. After heart transplantation, all transplant recipients received induction therapy with anti-thymocyte globulin and steroids.

\section{Immunosuppression}

Our immunosuppression protocol consists of an induction therapy designed to reduce the incidence of early rejection and is started 6 hours post-heart transplantation with intravenous anti-thymocyte globulin $1.5 \mathrm{mg} / \mathrm{kg}$ on the first 3 days accompanying intravenous prednisolone at $2.5-5 \mathrm{mg} / \mathrm{kg} / \mathrm{day}$. Thereafter, steroids are tapered at $2 \mathrm{mg} / \mathrm{kg} /$ day orally. Cyclosporine is started immediately preoperatively at $6 \mathrm{mg} / \mathrm{kg}$ orally and is continued at $2 \mathrm{mg} / \mathrm{kg}$ intravenously or $6 \mathrm{mg} / \mathrm{kg}$ orally to target a trough level of $250 \mathrm{ng} / \mathrm{mL}$. Mycophenolate mofetil (MMF) is started preoperatively at $1,000 \mathrm{mg}$ orally and is continued at $1,000 \mathrm{mg}$ twice daily either orally or intravenously. This triple therapy with cyclosporin/MMF/steroids is alternatively applied with everolimus $(2 \times 0.75 \mathrm{mg}$ orally daily, target trough levels $3-8 \mathrm{ng} / \mathrm{mL}$ ) instead of MMF (22), when there are episodes of acute rejection.

\section{Monitoring of graft rejection post-transplantation}

We employ non-invasive techniques of rejection monitoring in post-transplant children consisting of intramyocardial electrogram (IMEG) and echocardiography. The remotemonitoring IMEG system that has been developed by our group since $1986(23,24)$, which has become the major diagnostic tool in our facility, has an implanted telemetric pacemaker that allows daily long-distance surveillance of the electrocardiogram and records changes consistent with both cellular and humoral rejection in a highly reliable manner. In contrast to primary heart transplant patients in whom we implant IMEG with epicardial electrodes at the time of heart transplantation, we implant transvenous electrodes 1-2 weeks post-transplantation (when wound healing has been uneventful) in children who are bridged to transplant with VAD support. Rejection is assumed when a drop of $>10 \%$ of the mean QRS-amplitude occurs, paralleled by an increase of heart rate in both electrodes in 3 consecutive days. Anti-rejection therapy is immediately initiated when tissue Doppler echocardiography in a pulsed-wave mode reveals impairment of early diastolic LV wall relaxation concomitant with QRS amplitude loss. A new Doppler imaging technology is "echocardiographic 
strain and strain rate imaging", which enables more reliable and comprehensive assessment of myocardial function with its ability to differentiate between active and passive movement of myocardial segments, as well as to quantify intraventricular desynchrony and evaluate longitudinal myocardial shortening. Its high sensitivity in the assessment of myocardial viability is helpful in detecting acute allograft rejection and early occurrence of transplant coronary artery disease after heart transplantation (22). We do not perform endomyocardial biopsy in paediatric transplant patients.

\section{Statistical analysis}

Data was analyzed using IBM SPSS version 24.0 software (IBM Armonk, New York, USA). Continuous variables were reported as means \pm standard deviation, median and range/IQR as appropriate, and compared using analysis of variance. Categorical data were reported as relative frequencies and percentages, and compared using the chi-square test. The influence of risk factors such as age, gender, diagnosis, and mode of support (LVAD or BVAD) on the primary outcome was assessed by Chi-square analysis and paired $t$-tests. The follow-up data was complete, and no patients were lost to follow-up. Time-related event data (mortality and survival) were analyzed using the KaplanMeier estimates at $95 \%$ confidence interval. Survival statistics for subgroups were compared using the LogRank (Mantel-Cox) test. A P value of $<0.05$ was considered statistically significant.

It's important to note that for the purpose of comparison of post-transplant survival of children with heart failure supported with VAD, survival data (pending publication) of 201 children [mean age $9.4(10.3 \pm 7.6)$ years; IQR: 3.7-15.11 years] who underwent primary heart transplantation after a median transplant waiting time of 54.85 days (range, 1-354 days) has been briefly cited in this report.

\section{Results}

\section{Morbidity in children on VAD before heart transplantation}

Mediastinal re-exploration because of bleeding was necessary in $10(7.8 \%)$ patients. Overall, pump exchange was necessary 45 times. With the introduction of a modified anticoagulation regimen in 2000 , the rate of pump exchange has decreased despite significantly longer support times. The main reason for pump exchange was thrombus formation in the valves. Pump exchange, performed in the operating theatre, has been proved to be a safe procedure; no complications occurred during pump changes.

No children suffered from mediastinitis, even in those who required re-exploration. There was no instance of technical failure, neither of the blood pump components nor of the driving system. However, skin infections around the cannulae occurred in 2 patients (2.5\%), pulmonary infections occurred early post-implantation in $3(3.6 \%)$, cerebral thromboembolism in $9(11.1 \%)$ and cerebral haemorrhage in $3(3.6 \%)$, confirmed by cerebral computerized tomography. These rates remain a troubling aspect generally associated with any kind of VAD support. Fortunately, on posttransplant follow-up, permanent neurological sequelae were not detected on clinical examination.

\section{Post-VAD orthotopic heart transplantation}

All 78 children supported with VAD pre-transplant eventually underwent orthotopic heart transplantation, after a mean duration of VAD support of $59(133.37 \pm 191.57)$ days (IQR: 23-133 days). Our reported longest duration of support with the Berlin Heart EXCOR was 856 days (16) in a 5-year-old boy after Norwood and Glenn procedures for hypoplastic left heart syndrome, mitral valve dysplasia and aortic atresia. Likewise, it is also worth mentioning a 14-month-old boy with decompensated dilative cardiomyopathy remained stable with the BVAD for 547 days until heart transplantation. In both these patients, the original Berlin Heart EXCOR pump was switched to a larger pump to accommodate somatic growth and haemodynamic demands. Yet at the time of this report, the longest duration of VAD support was 941 days before heart transplantation.

\section{Post-transplant survival}

Mean duration of follow-up is $9.4(10.3 \pm 7.6)$ years (IQR: 3.74-15.14 years; range, 3-29.9 years).

\section{Thirty-day mortality}

Early mortality occurred in five patients who succumbed to death secondary to right heart failure $(n=1)$, multiple organ failure $(\mathrm{n}=2)$, sepsis $(\mathrm{n}=1)$ and acute respiratory distress syndrome $(\mathrm{n}=1)$. 


\begin{tabular}{|c|c|c|c|c|c|c|c|c|}
\hline Categ?r? & 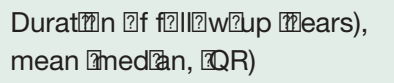 & 30民da?s & 1雨ear & 5雨ears? & 10雨ears & 15犆ears & 20象ears & 25畨ears? \\
\hline 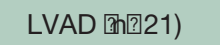 & 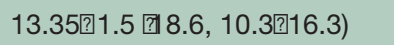 & 98.0?0.01 & 90.1 ?0.04 & 83.8?0.05 & 67.4 ? 0.08 & 57.8 ? 0.11 & 28.9 ?30.21 & ? \\
\hline 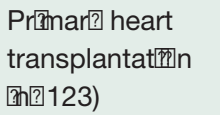 & 11.8? 8.0雨 2.1, 原.7?17.9) & 91.9구2.5 & 84.6?구.3 & 78.8?3.7 & 66.3 ? 4.4 & 53.6 ? 4.9 & 46.7包5.1 & 39.1 6.0 \\
\hline
\end{tabular}

\section{Late mortality}

Mortality over time is shown in Table 2. Twenty-two (28.2\%) patients died during the course of follow-up. Long-term post-transplant mortality was not related to VAD therapy. Post-transplant mortality included graft-related causes (chronic rejection $n=7$, primary or non-specific graft failure $\mathrm{n}=6$ ) and non-graft-related causes including multisystem organ failure, $(n=3)$, infection $(n=3)$, trauma $(n=2)$, and suicide $(\mathrm{n}=1)$.

\section{Cumulative survival}

Cumulative survival rates of patients bridged to transplantation with VAD were $93.6 \% \pm 2.8 \%, 84.6 \% \pm 4.1 \%, 79.1 \% \pm 4.7 \%$, $63.8 \% \pm 6.2 \%, 61.6 \% \pm 7.1 \%$ and $52.1 \% \pm 9.3 \%$ at 30 days, 1 , $5,10,15$, and 20 years, respectively (Figure $2 A$ ).

There is no statistically significant difference $(\mathrm{P}=0.79)$ in survival rates of patients bridged to heart transplantation with VAD compared to patients who underwent primary heart transplantation (Figure 2B).

\section{Post-transplant survival stratified according to the VAD implanted}

Likewise, there was no significant difference found $(\mathrm{P}=0.93)$ in the post-transplant survival rates of children according to the type of ventricular devices used (Berlin Heart EXCOR, HeartWare, Berlin Heart INCOR and Toyobo) to bridge them to heart transplantation (Figure 2C). Furthermore, post-transplant survival rates of LVAD and BVADsupported children did not achieve statistical significance when compared $(\mathrm{P}=0.73)$ (Figure $2 D)$.

\section{Age-stratified post-transplant survival}

Children who were bridged to transplantation were stratified according to age group, i.e., $0-1,1-5,5-10,10-15$ and $>15$ years old (Table 3). Comparison of post-transplant survival rates among the different age groups (Figure 3) were not statistically significant $(\mathrm{P}=0.33)$

\section{Gender stratified post-transplant survival}

There was no significant difference in survival rates $(\mathrm{P}=0.523)$ at 10 and 20 years between genders (female: $61.3 \pm 0.03$ and $46.6 \pm 0.12$ years; male: $71.0 \pm 0.08$ and $44.0 \pm 0.19$ years) (Figure 4 ).

\section{Diagnosis-stratified post-transplant survival}

Interestingly in this series, the post-transplant survival rates of children transplanted for end-stage heart failure of different aetiologies did not show any statistically significant differences i.e., congenital $(\mathrm{P}=0.08)$, dilative cardiomyopathy $(\mathrm{P}=0.59)$, myocarditis $(\mathrm{P}=0.50)$ (Figure 5).

\section{Rejection-related post-transplant survival}

Acute humoral transplant rejections (range, 5-20 episodes, ISHLT rejection grade $1 \mathrm{R}-3 \mathrm{R}$ ) occurred in 49 children (mean age $6.8 \pm 5.1$ years; range, $0.4-14.6$ years) bridged to transplantation with VAD.

However, no statistical significance was found when post-transplant survival rates were compared to those who did not have episodes of rejection. Overall posttransplant survival of patients bridged to transplantation 

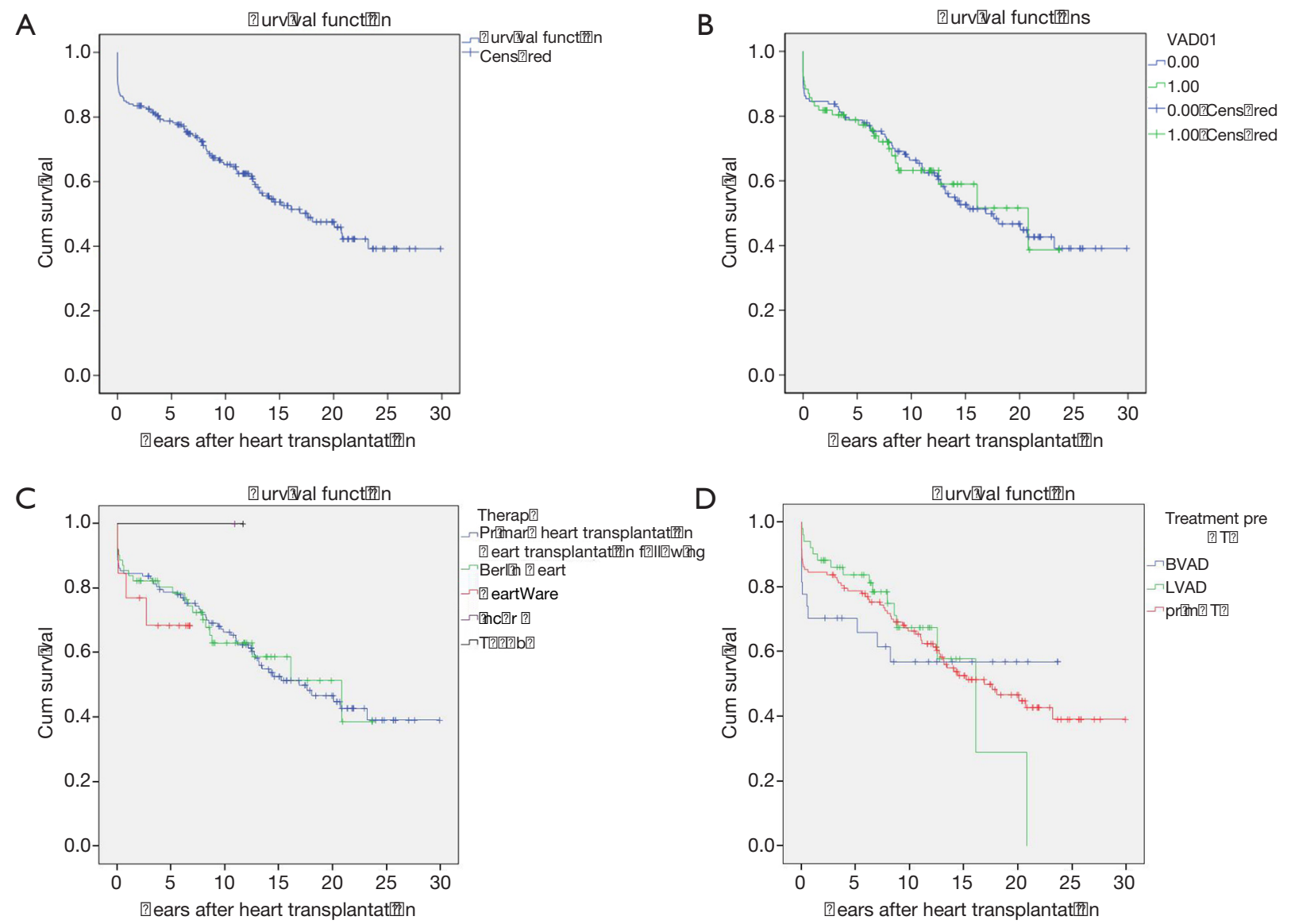

Figure 2 Kaplan-Meier estimates at 95\% CI showing. (A) Cumulative post-heart transplantation survival rate of 201 children; (B) survival comparison between patients bridged to heart transplantation with ventricular assist device and patients who underwent primary heart transplantation; (C) survival comparison of patients bridged to transplantation with various ventricular assist devices; (D) survival comparison between patients bridged to transplantation with LVAD and BVAD and primary heart transplantation. 0, no VAD (primary heart transplant); 1, with VAD; VAD, ventricular assist device; LVAD, left VAD; BVAD, biventricular VAD; primHTx, primary heart transplantation.

with VAD stratified according to post-transplant rejection at mean follow-up duration of $17.10 \pm 1.47$ years (range, $13.8-19.5$ years) was $65.1 \% \pm 0.6 \%$ and $49.1 \% \pm 0.7 \%$ at 10 and 20 years $(\mathrm{P}=0.67)$ (Table 3, Figure 6).

\section{Discussion}

Our study focused on the survival outcomes of children who were bridged effectively to transplantation and demonstrated that post- transplantation outcomes are similar to those not requiring support with a VAD (22), similar to the findings by Eghtesady et al. (25). Age at VAD implantation, gender, or etiology of heart failure did not appear to influence long-term post-transplant survival. Likewise, the type of VAD system and number of ventricles supported did not seem to impact on long-term posttransplantation outcome. These results reinforce the role of VADs in bridging children with advanced heart failure to heart transplantation.

The use of VADs as bridge to transplantation has gained popularity over the last decade. It is now recognized as an integral treatment modality in end-stage heart failure on those awaiting heart transplantation. When implanted in the appropriately chosen patient, it is superior to medical treatment alone and has shown non-inferiority to heart transplantation while optimizing functional status and preserving end organ function.

Numerous reports (26-33) have validated that VADs can successfully bridge adult and paediatric heart failure patients to heart transplantation, regardless of the primary 


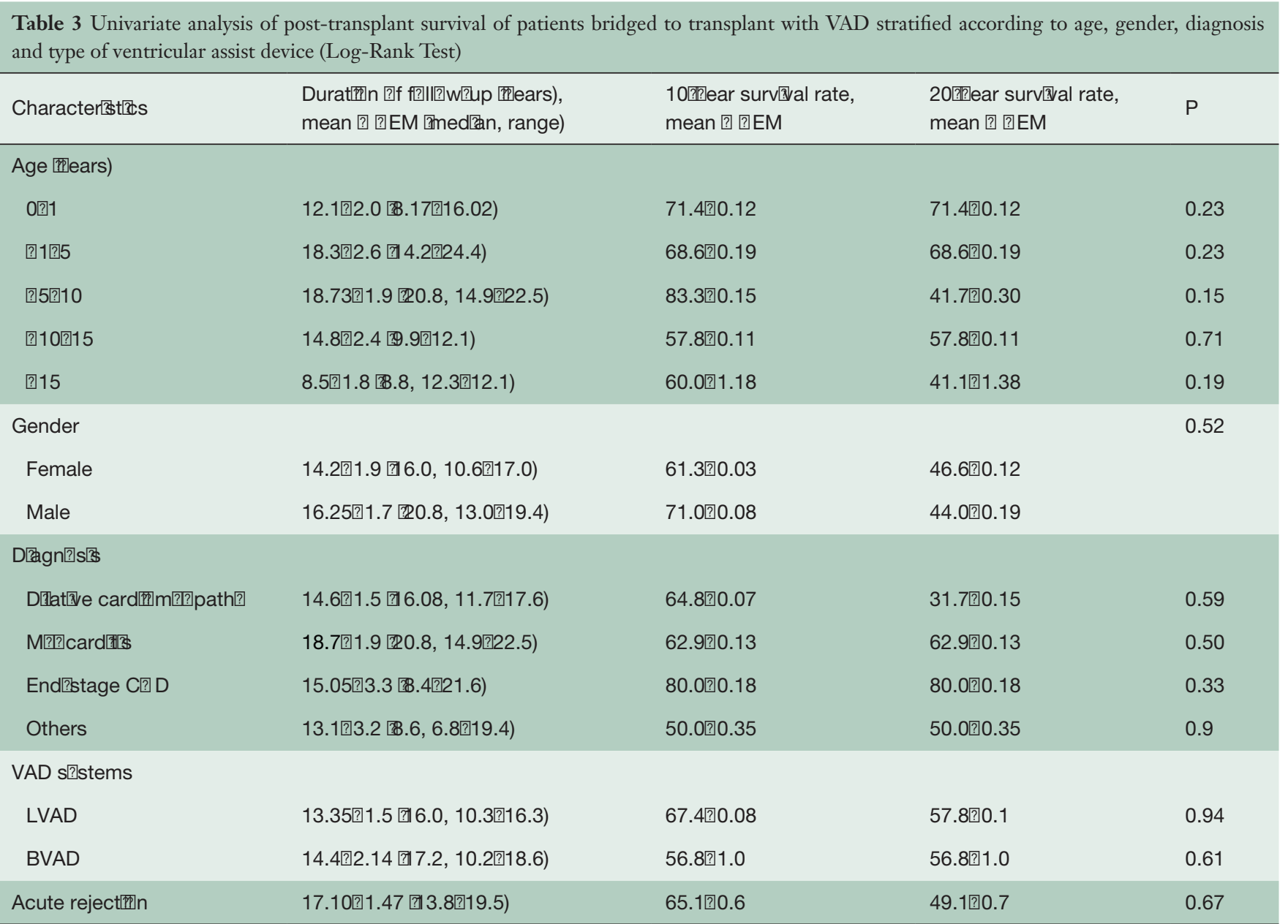

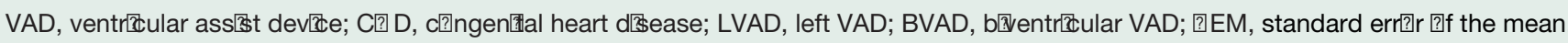

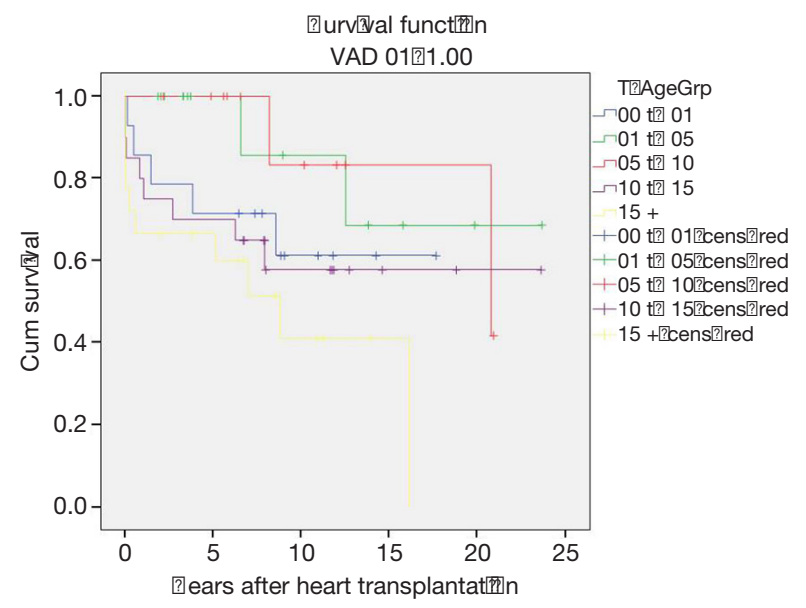

Figure 3 Kaplan-Meier estimates at $95 \%$ CI showing agestratified survival of patients bridged to heart transplantation with ventricular assist devices. aetiology of heart failure, i.e., DCMP, myocarditis, postcorrection of CHD, or end-stage CHD. This is equally justified in patients suffering from tumour-related toxicity, in whom support with VAD has been essential to render them to a state of transplantability, as in our series. Lorts et al. (28) reported that there was no difference in 5-year survival after transplantation for children on VAD at the time of transplant, compared with those not requiring VAD. De Rita and colleagues (29) in their series of 92 children likewise reported that bridging children to heart transplantation with mechanical circulatory support of any type does not alter the overall likelihood of a successful outcome, be it recovery of cardiac function or orthotopic heart transplantation. The report by Wehman et al. (30) strengthened this finding and stated that children who received VADs as a bridge to transplant had a similar 


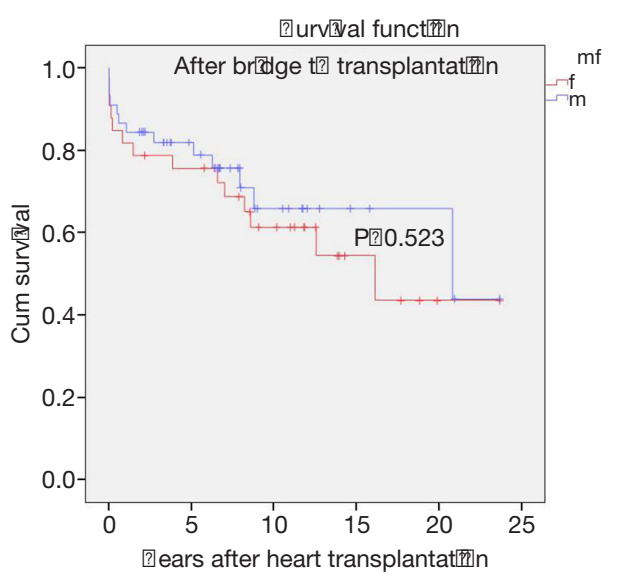

Figure 4 Kaplan-Meier estimates at 95\% CI showing genderstratified survival of patients bridged to heart transplantation with ventricular assist device. $m$, male; $f$, female.

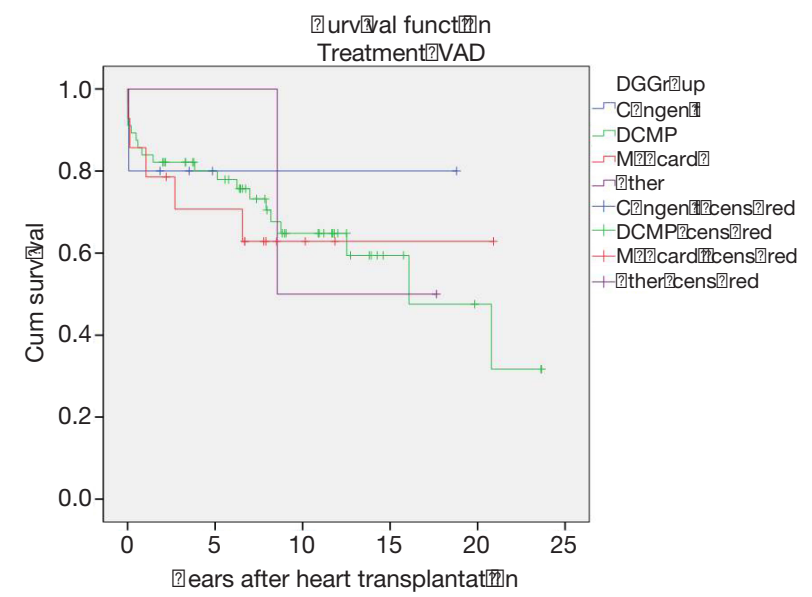

Figure 5 Kaplan-Meier estimates at 95\% CI showing diagnosisstratified survival of patients bridged to heart transplantation with ventricular assist device. Congenit, congenital; DCMP, dilated cardiomyopathy; Myocardi, myocarditis.

midterm (3 years) post-transplant survival compared to those undergoing direct heart transplantation. They added that these findings underscore the importance of continued evolution of device technology and translation of safe, effective miniaturized VADs into clinical practice. Likewise, Miller et al. (31) also reported that VAD had proven itself superior in terms of certain postoperative complications (cerebrovascular events, gastrointestinal bleeding, incidence of RV failure), survival, quality of life, and costs as a bridge to transplant in children.

Kindel et al. (32) analyzed outcomes from 204 children

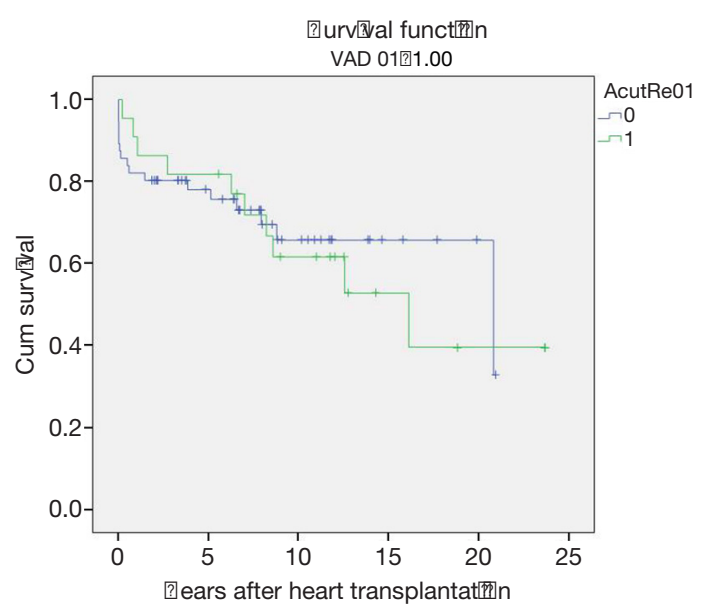

Figure 6 Kaplan-Meier estimates at 95\% CI showing rejectionstratified survival of patients bridged to heart transplantation with ventricular assist device. DG, diagnosis; AcuRe, acute rejection; 0, no rejection; 1 , one to several episodes of rejection.

implanted with the EXCOR device in the United States and Canada from 2007 to 2010 and reported that survival at 12 months after implantation was 75\%:64\% bridged to transplant, $6 \%$ explanted for recovery, and $5 \%$ alive on continued support. Chen et al. (33) reported on 37 children who were implanted with VADs, and demonstrated that it was a highly effective means of both bridging to transplantation and supporting patients after transplantation during hemodynamic crises. They added that greater availability of smaller and potentially implantable devices for children will serve to improve these treatment strategies, while potentially improving the substantial morbidity related to anticoagulation in the smallest patients. Morales et al. (34) presented the clinical outcomes for a retrospective series of 73 children supported with the Berlin Heart EXCOR as a bridge to transplantation at 17 North American centres, which is the largest single-device experience of VAD use in children reported from North America and is similar in scope to the series reported by our group (6). Their study demonstrated that the Berlin Heart EXCOR appears effective (77\%) in supporting children to transplantation or recovery. A larger series was reported by Holman et al. (35) on 420 patients from 75 institutions, who received mechanical circulatory support. Although their analysis included patients of all ages, they stated that among the patients implanted for the indication of bridge to transplantation, $33 \%$ were alive at 6 months, $42 \%$ had been transplanted, $22 \%$ had died, and $3 \%$ had recovery of 
their native heart with device explantation. The prevalence of transplantation at 6 and 12 months post-implant was similar among patients bridged to heart transplantation with LVAD-only or BVAD support. All these aforementioned studies confirmed that there is a definite role for VAD therapy in patients with end-stage heart failure.

Anticoagulation and its monitoring remain a major problem despite significant progress. Heparin coating with CARMEDA bioactive surface alone has not solved all the problems. Pumps had to be exchanged when significant thrombus formation became visible. In one particular case, following a frustrating period of multiple pump thrombi under intravenous unfractionated heparin, we switched to low molecular weight heparin with monitoring of heparin anti-Xa activity. Since then, children requiring long-term anticoagulation on a VAD have been treated with low molecular weight heparin, allowing for a more stable level of anticoagulation without thromboembolic events. The reported high rates of device-related morbidity in children, particularly thromboembolic and haemorrhagic events, are of concern. It is likely that management of anticoagulation is the most important causal factor. Achieving effective anticoagulation in the smallest children is very difficult, because of both intrinsic factors related to maturation of the coagulation cascade and reasons related to the logistics of drug administration and frequent blood sampling (16).

Adverse events such as postoperative bleeding, neurological events, and thromboembolism in this series, however, occurred with a lower frequency. We did experience a high incidence of fibrin or thrombin deposition in the blood pumps requiring pump changes. Some of these problems have been attributed to technical issues, such as left atrial cannulation, which is a known risk factor for stroke. The Berlin Heart EXCOR blood pumps are manufactured in multiple sizes, obviating large stroke volumes in small children. The use of polyurethane valves instead of mechanical valves is less thrombogenic, and transparent blood chambers allow for visual control of filling and emptying and detection of thrombotic deposits through transillumination. Nevertheless, despite adherence to a strict anticoagulation protocol, neurological event and pump exchanges owing to thrombus formation occurred. The mechanism of stroke in VAD patients may be haemorrhagic or embolic. Embolic strokes predominate due to the prothrombotic surface of the VAD and the possible embolization of thrombus presumably from the LV cavity or dislodged from the pump itself. However, the majority of the neurological events were mild and did not preclude transplantation, without any permanent neurological sequelae detected on clinical examination during long-term follow-up.

It is widely recognized that the Berlin Heart EXCOR has ushered in the era of VAD therapy as a bridge to transplant. It is used in paediatric patients with single- or biventricular heart failure who are candidates for heart transplant. Age, gender, or diagnosis do not circumscribe its use. Berlin Heart INCOR, which is usually applied in adults, may also be implanted in adolescents of larger size. Other VAD systems such as HeartWare have followed, albeit data on its long-term performance is still awaited. In the United States, the DeBakey VAD Child (MicroMed Technology Inc., Houston, TX, USA) is currently the only Food and Drug Administration-approved VAD designed for use in children, but its approval is limited to children aged older than 5 years and with a body surface area (BSA) greater than $0.7 \mathrm{~m}^{2}$. The DeBakey VAD is able to support the LV effectively but has not been widely applied owing to thromboembolic issues (33). In our series, we have primarily used Berlin Heart EXCOR to bridge children to heart transplantation and we deemed it is not necessary nor it is ethical to compare the post-transplant outcome of its use to that of other devices, which were applied in fewer patients.

Isolated LVAD implantation may be sufficient for bridging some children to transplantation, even in the face of significant preoperative RV dysfunction. Such therapy allows for maximal unloading of the LV, which can appreciably reduce the afterload of the right ventricle. Combined with pharmacological right heart support, the need for additional ventricular support may become more limited. It is believed that patients requiring biventricular VAD support are a special group because they have more end-organ dysfunction and more advanced heart failure. This was not observed in the present series, wherein children who had a single- or BVAD support had similar long-term post-transplant survival. Although we acknowledge that only one-third of patients received biventricular support, the preoperative characteristics and demographics are similar to those children who received a single ventricle support. Other studies have demonstrated that increased risk of death is associated with biventricular support $(35,36)$. It has been speculated that having two devices in a small child, regardless of the pre-implantation clinical state, increases the morbidity profile, especially the thromboembolic rate. The St. Louis group (37) advocated implantation of BVAD in all patients, recognizing the 
fact that this aggressive approach obviates the risk of heart failure after LVAD implantation and significantly simplifies postoperative management. The group believed that elimination of RV dysfunction completely decreases postoperative bleeding, secondary to improved liver function, limits renal dysfunction, and allows earlier extubation, thus enabling earlier intensive care unit discharge and enhanced mobilization. Support for this strategy originated from previous adult VAD experience (38-41). These studies suggested that apparently poorer outcomes with biventricular support were confounded by patients who primarily underwent LVAD implantation, later followed by right VAD implantation due to onset of RV failure.

We have stratified the children in this series according to age group, to determine whether younger age during VAD implantation is associated with decreased survival, and our findings revealed that all age groups have similar longterm post-transplant survival. This is in contrast with the findings of Morales et al. (34), who reported that younger age and use of biventricular VAD support were risk factors for mortality. They justified their finding as probably due to their small cohort and relatively low number of total deaths, leaving their study underpowered, and that the influence of young age on mortality risk may have emphasized the lack of understanding in anticoagulation management and monitoring in small children with cardiac devices. The authors added that some of the difficulty in anticoagulating this cohort is undoubtedly secondary to age-related maturation of the coagulation and fibrinolytic systems and the more complex requirements for medication administration.

This multi-institutional analysis on outcome of patients with VAD demonstrated that there were no significant differences in survival at 1, 3 or 5 years by sex or race and no differences in time-related freedom from stroke, driveline infection, gastrointestinal bleeding or pump thrombus by sex or race, and neither sex nor race was associated with survival (42). Another group reported that female patients aged above 13 years are underrepresented in the population of mechanical circulatory patients and, when they are supported, VAD implantation is more often under emergency circumstances. The authors concluded that gender had a significant impact on 5-year survival (43). These studies were all conducted in adult patients with VADs and not necessarily in those patients bridged to transplant with VAD. There have been no studies that analyze the influence of gender in children supported with
VAD. When we considered the impact of gender on longterm post-transplant survival in children with VAD, we did not find any difference, even when further stratified according to age, diagnosis, and type of VAD support. Future focused research should provide more insight into this issue.

A previous report from our group (44) stated that CHD is a risk factor for in-hospital mortality after VAD implantation. However, this was demonstrated when all VAD recipients were considered. In this series of children supported with VAD as bridge to transplantation, this was not the case. In fact, regardless of the diagnosis, even in those patients with single-ventricle physiology, posttransplant survival has been similar.

Findings related to graft rejection after VAD support have been attributed to potential sensitization emanating from VAD support $(45,46)$. We regarded allosensitization to play a key role in management of children being bridged to transplant with a VAD; hence, it has been our routine to desensitize these patients. VAD-implanted adult patients are known to be at risk for developing antibodies to human leukocyte antigens, as detected by the panel reactive antibody test (47). An immune dysfunction secondary to VAD implantation fortified the increased formation of HLA antibodies and the susceptibility to systemic infections. LVAD implantation leads to a multifactorial dysregulatory process involving intensified T-cell apoptosis, unopposed production of TH2 cytokines, and selective loss of TH1 type $\mathrm{T}$ cells. As a consequence of circulating anti-HLA class I and class II antibodies, LVAD recipients are subject to repeated positive cross-matches, increased waiting time to cardiac transplantation, and increased risk of cellular rejection after transplantation (48). Although some studies have proposed an atypical activation-induced $\mathrm{T}$-cell death and B-cell hyperreactivity as a possible mechanism of enhanced production of HLA antibodies, most likely evoked by the textured internal surface of the VAD or the neointima formation after implantation (47), the paediatric VAD population is quite different, depending on sensitization exposures and developmental immaturity of the immune system. We believe that the immaturity of the immunological system in very young children could lead to sensitization. Hence, we adhered to routine panel reactive antibody level monitoring during VAD support and after heart transplantation, as well as a more aggressive immunosuppressive treatment protocol, to prevent acute rejection in sensitized patients.

Noteworthy in this series was that in two patients 
with extremely elevated pulmonary vascular resistance unresponsive to pulmonary vasodilator therapy, pulmonary vascular resistance normalized after prolonged VAD support. Pulmonary vascular resistance was normal without pulmonary vasodilators in both patients soon after heart transplant. It may be assumed that continuous unloading of the LV, which thereby lowers left atrial pressure, is the theoretical basis for VAD implantation in these patients to improve their pulmonary hypertension. This theory has been substantiated in adult patients (49). High pulmonary vascular resistance seems to be amenable to significant improvement with the help of VAD support for the failing LV. Adequate reduction of pulmonary resistance can be expected within 3 to 6 months of implanting a LVAD in end-stage heart failure children awaiting heart transplant.

With increasing experience, the Berlin Heart EXCOR has evolved to be the most widely used mechanical circulatory support system in infants and children with heart failure. Prolonged support time allows those children being treated for malignancy to reach a transplantable status by documentation of a sufficiently long tumour-free period to justify listing for heart transplantation.

Implantation of VAD in children with single ventricle physiology post-staged palliation may be demanding in the presence of several anastomoses, shunts, grafts and conduits, to correctly position the inflow (positioned in the systemic ventricle) and outflow cannulae. The implantation of the uniVAD on the right side has been described in a failing Fontan by Prêtre et al. (17). Nathan et al. (50) inserted biventricular assistance after failing cavopulmonary anastomosis in a Norwood-Fontan pathway. This group was able to reconnect the superior vena cava to the right atrium, and implanted the cannulae in the usual fashion. Two other groups inserted a paracorporeal assist device in the apex of the $\mathrm{LV}$ after failing conversion to a total or partial cavopulmonary connection $(51,52)$. In both situations, the main problem was a failing driving ventricle after surgery. A LVAD reduces the pressure in the left atrium and indirectly the venous and lymphatic congestion. Even though reduction of the venous pressure has a significant impact in a Fontan circulation, the benefit of this approach remains limited in failing pulmonary circulation and would probably not have rescued an acutely ill patient. The only drawback of Prêtre's montage is the impossibility of measuring the evolution of pulmonary vascular resistance, which is typically elevated in failing Fontan patients (53). The more physiological distribution of blood within the lungs with pulsatile flow and reduction of the lymphatic congestion may be expected to reduce the resistance.

\section{Perspectives}

Prompted by the continuous demand for device miniaturization, small-sized adult devices are currently in development, which may facilitate the way for greater assimilation in the pediatric population. Implantable continuous-flow VADs may finally reach small children. The HeartMate 3 (St. Jude Medical, Inc.) is now in its primary clinical application in children. It is able to provide flows between 2.5 and $10 \mathrm{~L} / \mathrm{min}$, as well as an artificial pulse by alternating the pump rotor speed once every other second (54). Furthermore, the MVAD (HeartWare Inc.) is currently in its clinical application. It has a displacement volume of $20 \mathrm{~mL}$ and weighs $<100 \mathrm{~g}$. Its speed ranges from 8,000 to $18,000 \times \mathrm{g}$, and it can deliver blood flow between 1 and $7 \mathrm{~L} / \mathrm{min}$ at a pressure of $75 \mathrm{mmHg}$ (55). Considering the size of the device, the MVAD may potentially be applied as pediatric VAD support. Finally, the Jarvik Infant (Jarvik Heart Inc., New York, NY, USA) is an implantable continuous-flow VAD specifically designed for small children. Hemolysis had been the cause of its previous withdrawal, leading to the disapproval of Investigational Device Exemption applications. However, recently it has undergone significant design overhaul. The new Jarvik Infant 2015 was reintroduced, and the size of inflow cannula has increased from 11 to $15 \mathrm{~mm}$. This long-awaited device is currently undergoing preclinical testing and upon its completion, it will be evaluated in the PumpKIN trial (pumps for kids, infants, and neonates) funded by the National Heart, Lung, and Blood Institute, a subsidiary of the National Institutes of Health. This trial is intended to be randomly allocated to receive either the Berlin EXCOR or the Jarvik Infant 2015 device, with each group consisting of 44 patients. The success of this trial may pave the era of the use of implantable continuous-flow VADs in small children (56).

\section{Conclusions}

These results demonstrate that VADs can adequately support paediatric patients as a bridge to heart transplantation. These patients have a comparable long-term post-transplant survival as those undergoing primary heart transplantation. These findings underscore the importance of continued evolution of device technology, which may further improve the outcomes 
in this population.

\section{Acknowledgements}

We are grateful with the statistical assistance of Dr. Dietmar Böthig of Hannover Medical School, Germany.

\section{Footnote}

Conflicts of Interest: The authors have no conflicts of interest to declare.

Ethical Statement: The Institutional Review Board approved this retrospective study (2017/P-7690) and waived the need for patient consent.

\section{References}

1. Warnecke H, Berdjis F, Hennig E, et al. Mechanical left ventricular support as a bridge to transplantation in childhood. Eur J Cardiothorac Surg 1991;5:330-3.

2. Hennig E. Design criteria for pediatric mechanical circulatory support systems (PMCSS). In: Ferrazzi P, Parenzan L. editors. Annals of the Concerted Action HEART 1991-1992. Bergamo, Italy: Commission of the European Communities, 1991:30-43.

3. Hetzer R, Loebe M, Potapov EV, et al. Circulatory support with pneumatic paracorporeal ventricular assist device in infants and children. Ann Thorac Surg 1998;66:1498-506.

4. Hetzer R, Loebe M, Weng Y, et al. Pulsatile pediatric ventricular assist devices: Current results for bridge to transplantation. Semin Thorac Cardiovasc Surg Pediatr Card Surg Annu 1999;2:157-76.

5. Alexi Meskishvili V, Hetzer R, Weng Y. The use of the Berlin Heart in children. In: Duncan B. editor. Mechanical Support for Cardiac and Respiratory Failure in Pediatric Patients. New York: Marcel Deker, 2001:287-313.

6. Hetzer R, Potapov EV, Stiller B, et al. Improvement in survival after mechanical circulatory support with pneumatic pulsatile ventricular assist devices in pediatric patients. Ann Thorac Surg 2006;82:917-24.

7. Hetzer R, Stiller B. Technology insight: use of ventricular assist devices in children. Nat Clin Pract Cardiovasc Med 2006;3:377-86.

8. Hetzer R, Alexi-Meskishvili V, Weng Y, et al. Mechanical cardiac support in the young with the Berlin Heart EXCOR pulsatile ventricular assist device: 15 years' experience. Semin Thorac Cardiovasc Surg Pediatr Card
Surg Annu 2006:99-108.

9. Hetzer R, Potapov E, Alexi-Meskishvili V, et al. Singlecenter experience with treatment of cardiogenic shock in children by pediatric ventricular assist devices. J Thorac Cardiovasc Surg 2011;141:616-23.

10. Hetzer R, Miera O, Photiadis J, et al. Heart transplantation after longest-term support with ventricular assist devices. Ann Thorac Surg 2014;98:1814-5.

11. Merkle F, Boettcher W, Stiller B, et al. Pulsatile mechanical cardiac assistance in pediatric patients with the Berlin heart ventricular assist device. J Extra Corpor Technol 2003;35:115-20.

12. Hetzer R, Weng Y, Potapov EV, et al. First experiences with a novel magnetically suspended axial flow left ventricular assist device. Eur J Cardiothorac Surg 2004;25:964-70.

13. Takano H, Taenaka Y, Nakatani T, et al. Development and evaluation of ventricular assist blood pump to salvage patients with profound heart failure. Nihon Kyobu Geka Gakkai Zasshi 1989;37:2072-81.

14. Taenaka Y, Takano H, Nakatani T, et al. Ventricular assist device (LVAD) for children: in vitro and in vivo evaluation. Trans Am Soc Artif Intern Organs 1984;30:155-8.

15. Takano H, Nakatani T, Taenaka Y, et al. Treatment of acute profound heart failure by ventricular assist device. Jpn Circ J 1992;56:100-10.

16. Hetzer R, Kaufmann F, Delmo Walter EM. Paediatric mechanical circulatory support with Berlin Heart EXCOR: development and outcome of a 23-year experience. Eur J Cardiothorac Surg 2016;50:203-10.

17. Prêtre R, Haussler A, Bettex D, et al. Right-sided univentricular cardiac assistance in a failing Fontan circulation. Ann Thorac Surg 2008;86:1018-20.

18. Koster A, Huebler S, Potapov E, et al. Impact of heparininduced thrombocytopenia on outcome in patients with ventricular assist device support: single-institution experience in 358 consecutive patients. Ann Thorac Surg 2007;83:72-6.

19. Potapov EV, Ignatenko S, Nasseri BA, et al. Clinical significance of PlA polymorphism of platelet GP IIb/IIIa receptors during long-term VAD support. Ann Thorac Surg 2004;77:869-74; discussion 874.

20. McKenna DH, Eastlund T, Segall M, et al. HLA alloimmunization in patients requiring ventricular assist device support. J Heart Lung Transplant 2002;21:1218-24.

21. Yang J, Schall C, Smith D, et al. HLA sensitization in pediatric pre-transplant cardiac patients supported by mechanical assist devices: the utility of Luminex. J Heart 
Lung Transplant 2009;28:123-9.

22. Hetzer R, Weng Y, Delmo Walter EM. State of the art in paediatric heart transplantation: the Berlin experience. Eur J Cardiothorac Surg 2013;43:258-67.

23. Hetzer R, Potapov E, Müller J, et al. Daily non-invasive rejection monitoring improves long-term survival in pediatric heart transplantation. Ann Thorac Surg 1998;66:1343-9.

24. Warnecke H, Schüler S, Goetze HJ, et al. Noninvasive monitoring of cardiac allograft rejection by intramyocardial electrogram recordings. Circulation 1986;74:III72-6.

25. Eghtesady P, Almond CS, Tjossem C, et al. Posttransplant outcomes of children bridged to transplant with the Berlin Heart EXCOR Pediatric ventricular assist device. Circulation 2013;128:S24-31.

26. Sharma MS, Webber SA, Morell VO, et al. Ventricular assist device support in children and adolescents as a bridge to heart transplantation. Ann Thorac Surg 2006;82:926-32.

27. Davies RR, Haldeman S, McCulloch MA, et al. Ventricular assist devices as a bridge-to-transplant improve early posttransplant outcomes in children. J Heart Lung Transplant 2014;33:704-12.

28. Lorts A, Blume ED. Pediatric mechanical circulatory support: available devices and outcomes as bridgeto-transplant therapy. Curr Opin Organ Transplant 2015;20:557-61.

29. De Rita F, Hasan A, Haynes S, et al. Outcome of mechanical cardiac support in children using more than one modality as a bridge to heart transplantation. Eur J Cardiothorac Surg 2015;48:917-22; discussion 922.

30. Wehman B, Stafford KA, Bittle GJ, et al. Modern Outcomes of Mechanical Circulatory Support as a Bridge to Pediatric Heart Transplantation. Ann Thorac Surg 2016;101:2321-7.

31. Miller JR, Eghtesady P. Ventricular assist device use in congenital heart disease with a comparison to heart transplant. J Comp Eff Res 2014;3:533-46.

32. Kindel SJ, Everitt MD. A contemporary review of paediatric heart transplantation and mechanical circulatory support. Cardiol Young 2016;26:851-9.

33. Chen JM, Richmond ME, Charette K, et al. A decade of pediatric mechanical circulatory support before and after cardiac transplantation. J Thorac Cardiovasc Surg 2012;143:344-51.

34. Morales DL, Almond CS, Jaquiss RD, et al. Bridging children of all sizes to cardiac transplantation: the initial multicenter North American experience with the Berlin Heart EXCOR ventricular assist device. J Heart Lung
Transplant 2011;30:1-8.

35. Holman WL, Kormos RL, Naftel DC, et al. Predictors of death and transplant in patients with a mechanical circulatory support device: a multi-institutional study. J Heart Lung Transplant 2009;28:44-50.

36. Kirk R, Edwards LB, Aurora P, et al. Registry of the International Society for Heart and Lung Transplantation: Twelfth official pediatric heart transplantation report-2009. J Heart Lung Transplant 2009;28:993-1006.

37. Gandhi SK, Huddleston CB, Balzer DT, et al. Biventricular assist devices as a bridge to heart transplantation in small children. Circulation 2008;118:S89-93.

38. Hetzer R, Kaufmann MEng F, Potapov E, et al. Rotary Blood Pumps as Long-Term Mechanical Circulatory Support: A Review of a 15-Year Berlin Experience. Semin Thorac Cardiovasc Surg. Spring 2016;28:12-23.

39. Hetzer R, Delmo Walter EM. Rescue mechanical circulatory support for failing transplanted hearts. Eur J Cardiothorac Surg 2012;42:702-3.

40. Hetzer R, Delmo Walter EM. Existing issues and valid concerns in continuous-flow ventricular assist devices. Expert Rev Med Devices 2017;14:949-59.

41. Hetzer R, Krabatsch T, Stepanenko A, et al. Long-term biventricular support with the HeartWare implantable continuous flow pump. J Heart Lung Transplant 2010;29:822-4.

42. Meeteren JV, Maltais S, Dunlay SM, et al. A multiinstitutional outcome analysis of patients undergoing left ventricular assist device implantation stratified by sex and race. J Heart Lung Transplant 2017;36:64-70.

43. Potapov E, Schweiger M, Lehmkuhl E, et al. Gender differences during mechanical circulatory support. ASAIO J 2012;58:320-5.

44. Fan Y, Weng YG, Huebler M, et al. Predictors of inhospital mortality in children after long-term ventricular assist device insertion. J Am Coll Cardiol 2011;58:1183-90.

45. Malickaite R, Rucinskas K, Staneviciene A, et al. Sensitisation and post-transplant course after the implantation of ventricular assist device. Interact Cardiovasc Thorac Surg 2009;8:339-342; discussion 342.

46. Arnaoutakis GJ, George TJ, Kilic A, et al. Effect of sensitization in US heart transplant recipients bridged with a ventricular assist device: update in a modern cohort. J Thorac Cardiovasc Surg 2011;142:1236-45, 1245.e1.

47. O'Connor MJ, Menteer J, Chrisant MR, et al. Ventricular assist device-associated anti-human leukocyte antigen antibody sensitization in pediatric patients bridged to heart transplantation. J Heart Lung Transplant 2010;29:109-16. 
48. Schuster M, Kocher A, John R, et al. B cell activation and allosensitization after left ventricular assist device implantation is due to $\mathrm{T}$ cell activation and CD40 ligand expression. Hum Immunol 2002;63:211-20.

49. Haddad H, Elabbassi W, Moustafa S, et al. Left ventricular assist devices as a bridge to heart transplantation in congestive heart failure with pulmonary hypertension. ASAIO J 2005;51:456-60.

50. Nathan M, Baird C, Fynn-Thompson F, et al. Successful implantation of a Berlin heart biventricular assist device in a failing single ventricle. J Thorac Cardiovasc Surg 2006;131:1407-8.

51. Frazier OH, Gregoric ID, Messner GN. Total circulatory support with an LVAD in an adolescent with a previous Fontan procedure. Tex Heart Inst J 2005;32:402-4.

52. Newcomb AE, Negri JC, Brizard CP, et al. Successful left ventricular assist device bridge to transplantation after

Cite this article as: Hetzer R, Javier MF, Delmo Walter EM. Role of paediatric assist device in bridge to transplant. Ann Cardiothorac Surg 2018;7(1):82-98. doi: 10.21037/ acs.2018.01.03 failure of a Fontan revision. J Heart Lung Transplant 2006;25:365-7.

53. Khambadkone S, Li J, de Leval MR, et al. Basal pulmonary vascular resistance and nitric oxide responsiveness late after Fontan-type operation. Circulation 2003;107:3204-8.

54. THORATEC. Available online: http://media.sjm.com/ newsroom/news-releases/news-releases-details/2015/StJude-Medical-Announces-CE-Mark-Approval-for-theHeartMate-3-Left-Ventricular-Assist-System/default.aspx

55. HeartWare. HeartWare International Announces First Human Implants of the MVAD® System in CE Mark International Clinical Trial. Available online: http://www. biospace.com/news_story.aspx? StoryID=384895

56. Scheel JN. News from the PumpKIN Patch. Available online: www.ishlt.org/ContentDocuments/2014JulLinks_ Scheel.html 